\title{
Information and Communication Technology (ICT) in English Learning: through an Interactive Software-Website
}

\author{
Khoirul Anwar \\ English Education Department, University of \\ Muhammadiyah Gresik \\ anwarkhoirul41@gmail.com
}

\author{
Agus Wardhono \\ English Education Department, University of PGRI \\ Ronggolawe Tuban \\ agusward@gmail.com
}

\begin{abstract}
This study aims to produce an English learning model based on Information and Communication Technology (ICT) in the software development of competency form-based on learning materials to improve ability of English language equipped with teacher guidance and manual instruction through the use of an interactive software website. Using Research and Development $(R \& D)$ design, this study produces interactive English grammar software and $\mathrm{CD}$ for Structure courses that have been tested for its validity. This Software is for students of English Education Department to advance students' grammar skills. This learning can be accessed via internet wherever and whenever students want, so that they can answer the questions about English grammar problems. These specific e-learning materials include nine types of questions along with the use of key answers for teachers completed by valid test instruments. After the try outmaterials and suggestions for improvement, this e-learning website that has been formed can always be updated anytime and these materials of web-structure can be accessed through campus website. This research had encouraged students to freely access the structure learning materials and improve their grammar skills, which automatically improve their ability to master the four language skills which are listening, speaking, reading and writing.
\end{abstract}

Keywords - interactive software-website; grammar exercise

\section{INTRODUCTION}

The development of information technology and computers that are very rapid lately, is received a positive response in community since various services have implemented ICT (Information and Communications Technology). In business world it is known the terms of ebusiness or e-commerce, in the world of government known as e-government and for the world of education known as elearning.

In e-learning, Internet is a multi-purpose media, on one hand the Internet can be used to communicate interpersonally for example by using e-mail and chat as a means of communicating between personal (one-to-one communications), on the other hand with e-mail can also communicate with more than one person or a group of other users (one-to-many communications). The Internet also has an ability to facilitate discussion and collaboration activities by a group of people. In addition, with its ability to provide face-to-face communication (teleconference), enables Internet users to communicate audiovisual so that it is possible to have communication of verbal and non-verbal in real-time.

The proof of success of internet as a medium of learning was proposed by ref [1] and [2] stating that based on World Bank's 1997 report on Global Distance Learning Network (GDLN) program, e-learning development in American education is very effective and enables $30 \%$ better education, $40 \%$ Shorter, and $30 \%$ cheaper cost. Furthermore, in order for the lesson to be effective teaching, the use of ICT in classroom is needed because it gives impacts of increasing enthusiasm and high on-task behavior for students in doing task, because the students get novelty effect [3]

The Ministry of National Education as an organization that serves to manage education in Indonesia welcomes the development of ICT by incorporating a nuanced curriculum of introduction of information and communication technology, especially in secondary education. This response shows that the Ministry of National Education is concerned with rapid development of the world of information and communications technology. This policy aims to have students ability to know, understand, and interact with the world of information and communication technology, so that after the graduation is they will not be blind at all with the world of information and communication technology to live in community.

E-learning now has became the choice of education providers in various education circles because of its advantages including University of PGRI Ronggolawe (UNIROW) as one of the local private universities that are active in improving quality of teaching and learning process. Improvement of learning system begins with a shift of knowledge transfer process that initially tends to be more emphasis on teaching process, based on the content (content base), more abstract and only for certain groups (in this process, teaching tends to be passive) toward active process of Learning, based on problems (case base), contextual and not limited only for certain groups. In this learning process students are required to be more active by optimizing existing learning resources. 
Although e-learning has been considerable and potential to be utilized to improve quality of learning, but learning using computer media still cannot completely replace the role of teachers. Therefore, the use of learning media using computer needs to be combined with others so that it really gives positive results. In this case the use of ICT model is expected only to support learning activities at class, especially in grammar course for students majoring in English whose aim is to improve ability to write in English. This research and development of ICT model can also be considered as initial step for institution in order to organize e-learning based learning.

Development of Internet technology motivates progress of new instruments, content and systems in teaching and learning on campuses. The development of teaching and learning approach needs to be equipped with a new educational model where students can study independently anytime and anywhere. Only by connecting Internet, students can access course materials as supporting teaching and learning activities in classroom. At the same time lecturers may also be able to teach online.

Utilization of electronic technology in learning gives reinforcement to the pattern of changes in learning paradigm. E-learning system is a form of learning implementation that utilizes technology which is not limited by space and time. Thus this learning process can be done both with synchronous and asynchromous (done in different time). According to ref [4], the function of e-learning on teaching activities in classroom consists of three aspects, one is as the complement of conventional learning. In addition to serving as complement, e-learning also serves as a supplement (addition) and substitution (substitute). It is said to function as complementary (complementary / supportive) if the electronic learning material is programmed to complement the learning materials received by students in lecture forum [5]. That is, if there are students who have difficulty understanding subject matter presented by faculty in the classroom, they are given opportunity to utilize electronic learning materials. The goal is to make students more easily understand the subject matter presented by lecturers in the classroom.

\section{LITERATURE REVIEW}

\section{A. Onthology Design of E-learning Application}

-learning readiness factors used in reference to ontology establishment are the results of study of ref [6]. E-learning readiness is reviewed from eleven dimensions: policy, network, equipment, security, culture, human resources, financial, regulations, contents, standards, and management.

In general, ontology in e-learning is used to be a model learning content and to facilitate the process of rediscovering subject matter [7], to process matching answers and to personalize e-learning [8]. This requires an ontology for e-learning performance measurement [9]. Ontology is the existence of reasoning or ability in drawing conclusions. This conclusion can be utilized in providing recommendations based on measurement results. The use of ontology for measuring e-learning success has been developed by ref [9]. The study modeled Key Performance Indicator (KPI) in a company. Given some tests on employees and test results are modeled into ontology. The result is a prototype of e-learning performance measurement system. This prototype only measures the results of using elearning and does not include the process of measuring the readiness of the company in applying e-learning. Based on the description, the readiness of an institution in applying elearning is also a critical determinant of e-learning success. Therefore, an ontology design for the e-learning readiness measurement process will be developed. In this case, it is necessary to formulate the measurement of readiness of elearning implementation based on ontology above. Here is the formulation of ontology application of e-learning in FKIP University of PGRI Ronggolawe.

\section{B. The Implementation of e-Learning}

To implement e-learning, there are at least three components of e-learning, namely:

1) Infrastructure of e-learning, which can be a personal computer (PC), computer network, Internet and multimedia equipment including teleconference equipment when using synchronous learning services through teleconference.

2) E-learning systems and applications, ie. software systems to virtualize conventional teaching and learning process include how classroom management, materials or content creation, discussion forums, appraisal systems, exam systems and all features related to teaching and learning process management. Such software systems are often called Learning Management System (LMS). LMS is open-source so it can be used easily and cheaply to be developed in schools, universities, or other educational institutions.

3) E-learning content, is content and teaching materials that exist in e-learning system (Learning Management System). These content and teaching materials can be in the form of multimedia based content or text-based content (text-shaped content as in a regular textbook). The usual e-learning content is stored in the LMS so that it can be accessed by students anytime and anywhere.

The utilization of ICT for education, particularly English language learning, has became a necessity that cannot be delayed anymore. Various ICT applications are available in community and ready to be utilized optimally for educational purposes. Utilization of information and communication technology for education can be implemented in various forms in accordance with its function in education. According to ref [10], the function of information and communication technology in education can be divided into seven functions, namely (1) as a storehouse of knowledge, (2) as learning aids, (3) as 
educational facilities, (4) as competence standard, 5) as administrative support, (6) as school management tool, and (7) as educational infrastructure referring to the seven functions. It can be understood that ICT can contribute significantly to improving the quality of life of community, especially in education.

Similarly, learning English grammar can also be done through the virtual world (Internet) so that learning grammar can become more interesting. In the process of learning to teach English grammar has a very important role to support the four skills of English (listening, speaking, reading and writing). Therefore, innovative learning steps of ICT-based English grammar are needed.

Based on the results of preliminary observations that have been done by researchers at various universities in Tuban and Gresik indicate that so far there has been no lecturers who teach grammar through website. This is due to lack of knowledge of ICT-based learning media, even though they already have good infrastructure.

So far, grammar teaching courses are still dominantly conventional by using whiteboard with limited learning resources, and the teaching still focuses on lecturing. Grammar teaching is still memorizing not directly focused on competence to communicate. There is an assumption that if the learning process is done by only one medium, then stimuli of students that need to learn is very limited. This ICT learning model, students can access teaching materials that are made and kept by lecturers on website for 24 hours. Even the materials can be updated easily.

ICT-based English learning materials can support students with different levels of proficiency or special needs of students. Therefore, the researchers are interested to make design of ICT-based English grammar study in English Education Study Program. This ICT learning model is expected to improve ability to read and especially to write in English in correct grammar, especially in Tuban and Gresik.

In the future, the results of this research can contribute practical and theoretical benefits in grammar learning through e-learning for lecturers, students and institutions. The implementation of ICT-based grammar learning model is expected to assist in comprehending grammar material comprehensively in order to improve language skills, and can improve academic achievement. The use of ICT-based grammar learning model can improve teaching and learning process conducted in the classroom. On the other hand the product of learning model introduced can help lecturers to produce more effective learning. This research is conducted by an integrated team, so members must be from lecturers from different graduates of educational background. So the process of making this competency-based strategy will require a solid and unified team collaboration so as to form a comfortable academic atmosphere in FKIP environment of English Education. This research is expected to contribute significantly with the availability of innovative and compelling teaching materials that are competence-based for English lecturers in universities and used to improve students' English grammar skills which automatically increase ability of four speakers other than grammar and vocabulary.

\section{METHOD}

In order to develop teaching materials based on elearning in campus and off-campus environments, this study was selected based on research goals of material development by ref [11] in which to pilot the product using questionnaire for cross check. In order to strengthen and apply learning materials, this development of competencybased learning materials is to improve grammar skills for students majoring in English language education.

The stages of product development included are:

a) Initial Planning Stage Initial Planning Stage

The initial planning step is to conduct a preliminary research that is to observe the need by involving students as the subject in filling the questionnaire in four kinds of choices strongly agree, agree, disagree and totally disagree. In order to ensure that this research is important, discussions were held with some lecturers on the use of learning and development strategies of English learning in order to improve students' ability, as well as to conduct literature review and determine early skills of the students attending the subject of Structure I.

\section{b) Materials Development}

In this material development planning, the researchers begin to make four steps (a) flow chart, (b) the development of material into website, (c) consult with experts and (d) revise the development of English learning into website or upload to the web of E-learning at campus.

\section{c) Data Collection and Analysis}

Data were collected by literature study and quistioner in the form of four alternative quistioners: strongly agree, agree, disagree and strongly disagree, to find out whether the research is really needed by students or not based on students' need. Developing learning materials based on elearning: documents are collected through literature review, Internet sources, and from some respondents with a competency based so that students can have competence to answer questions from some exercises in Understanding English Grammar by Betty Azhar.

Limited trials were given to students to ensure the process run well. In this stage, training of introduction and use of e-learning or access to e-learning campus website for English lecturers from English Education Department was carried out. So directly through this training, researchers get suggestions and criticism for the improvement of e-learning website (lecturer of informatics engineering and lecturers of structure course) to form a website that can be practiced. Questioners are also distributed to students to see if the instrument is appropriate or not. 


\section{RESULTS}

The results of needs analysis from spreading questionnaire to 58 respondents consisting of 12 items of questions include the importance of grammar learning with exercises, grammar learning content and the level of difficulty, supporting media used, and the benefits of grammar learner media to students. The questionnaire was developed using a Likert scale where each respondent was asked to fill the approval level: $1=$ Never or almost never true, 2 = usually not true, $3=$ somewhat true, $4=$ usually true, 5 = Always or almost true.

First, the importance of grammar learning with exercises responded by $50 \%$ strongly agree and $21 \%$ agree, the grammar learning content and the difficulty level is $19.5 \%$ strongly agree and $60.5 \%$ agree, the supporting media used is $42.3 \%$ definitely agree and $31.6 \%$ agree, while the grammar learner's media benefit to students was $31 \%$ strongly agree and $42.1 \%$ agree.

Overall $33.5 \%$ strongly agree and $40.83 \%$ agree, so $74.33 \%$ of all respondents need grammar exercises that have difficulty level and appropriate to the media that is easy to use and can increase the spirit of learning nicely.

\section{A. Program Description}

This software program begins by entering the name of the learner to be able to operate the program. In this first menu not only the name is available but also another menu that is quit when we do not want to enter as in Fig. 1.

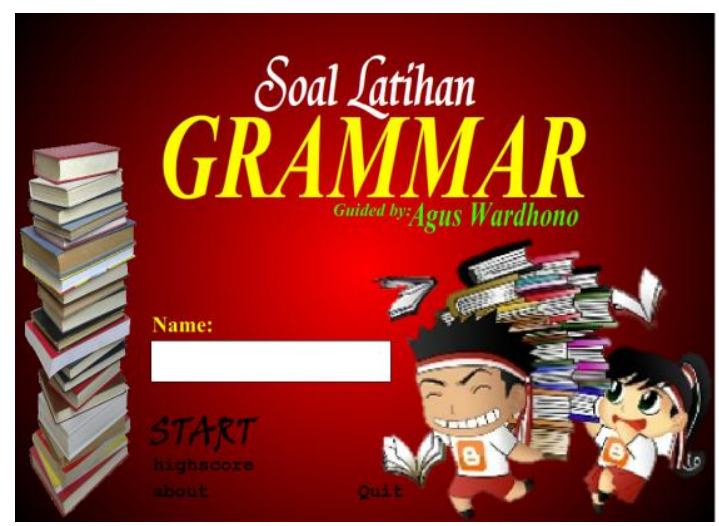

Fig. 1. The start menu program.

Users will be exposed to grammar questions that they generally know from grammar books that have been studied as seen in Fig. 2. Each question will have four choices that the users should choose and should be answered immediately which option he/she thinks is most appropriate within a minute (60 seconds). Once the user feels right with his/her choice then he/she has to click on one of the four options, which will automatically switch to the next question. So this procedure goes on to the last question that is the 50th question.

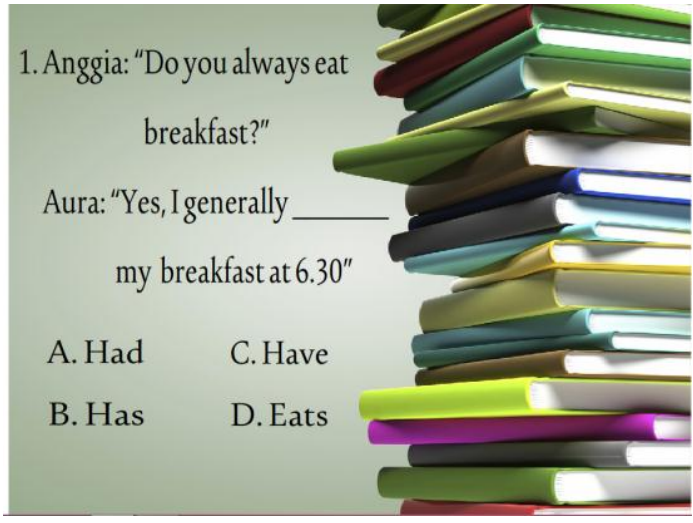

Fig. 2. Example of how to answer each grammar item.

The final step is to determine whether we have grammar mastery in answering the 50 questions that is to look at the last score. Users are said to be able and successful in doing these exercises if the final score is at least 60. If below this score, then the user is said to fail and may try again. The calculation of scores is designed automatically with the correct answers that have been attached to each item, so users do not need to manually unlock the answer as a paper test. All the items and answers have been developed into an integrated flash software, which can be downloaded through the website provided on campus so that every student can download anytime and anywhere.

\section{B. Response on Program}

In general, the questionnaire developed includes two important things, namely the content of the exercise material and the satisfaction of its use. The content of the material relates to the difficulty level (4.05), the use of the writing font (4.1), and the quality of the distractor option used (4.15). While the satisfaction of the use of exercise materials is related to curiosity (4.15), attention (4.25), likes (4.2), learning spirit (4.05), learning challenges (3.95), and ease of use (4.2). Overall the average response result about the quality of content and satisfaction of its use is 4.105. This means all respondents feel very satisfied with the software that has been developed to facilitate learning grammar.

The result of the use of grammar materials by this learner shows that although the program developed is simple but it can benefit grammar learning process through easy-to-use exercises and can be accessed anytime and anywhere. This program has also been validated by software development experts in this case people who have expertise in the field of informatics although there are some things that need to be optimized that is the implementation of this program against other subjects to get better reliability.

\section{DISCUSSION}

To strengthen the use of this technology, specific research conducted by ref [12] emphasize the use of conjuction by 19 students at Khon Kaen University of 
Thailand, where after experiments, web-based subject can improve grammar mastery, especially conjunction. Unfortunately, this research does not provide a detailed explanation of the way or learning strategy used explicitly so that there are remaining questions that need to be answered whether correct improvement in the ability of conjunction grammar mastery is due to the web media or because of learning strategies.

This has been stated by ref [13] who state that the use of web in learning leads more to an increase in learning desire, curiosity, involvement and learning challenge itself compared to the increase of learning material knowledge. Overall, web-based materials or resources provide many options for teachers or tutors to use, but using only the right strategies then learners will gain increased knowledge. So the problem is the strategy that is able to optimize the learning media, not the multimedia itself. Therefore, ref [14] provides clear steps in using web-based technology, where there are at least 3 important points in applying web-based learning that (1) must be able to provide space to the learner to optimize role in completing task, (2) able to make and optimize counseling process during learning between teacher and student, (3) there should be pedagogical communication which becomes the basis of tolerance and optimal participation. As long as these three processes do not occur then, the use of the web in learning will not have a good impact on learning.

The next interesting finding is from ref [15] who conducted experimental research on ESP learner in Iran especially in Tonekabon Payam Noor Univeristy, taking 98 samples. The experimental results show that Computer Assissted Language Learning (CALL) in grammar teaching does not always improve its mastery skills but has a positive impact on the participation of learning. With the learner character of ESP, CALL provides a stronger space for more learning opportunities to ESP learners that demonstrate the effectiveness of web-based CALL significantly. However, there is not enough information to say that a strategy or web-based multimedia has an important role to the effectiveness of learning.

As a whole, research development with various types in the use of web in grammar learning, as has been developed in this research, is needed especially to complete the previous information (by previous researchers) who have not given clarity on the role of the media, particularly webrole in learning. It should be emphasized here that, webbased learning media should be combined creatively with learning methods to achieve learning objectives themselves successfully. This is why the future researchers need to develop more models of integration of web-based learning methods and media because a model development of webbased learning media will not be $100 \%$ compatible to be adopted in different learning settings. The more development of web-based multimedia learning media rightly combined with precise teaching strategy will support the creativity of teachers and tutors and also the learners themselves.

\section{CONCLUSION}

The purpose of this study is to develop an ICT learning model that combines interactive software-website. After the need analysis, this web-based interactive software product has met content conformity elements especially difficulty level, and have the opportunity to encourage satisfaction in using the software in the learning of grammar exercises. The interactive development of this web-based software has been tailored to that need where there are 50 items of questions developed in which every single item takes 60 seconds to answer, completed as well by a final score of at least 60 to show the minimum limit of user ability. After the trial, this web-based interactive software development shows good acceptance, especially on the satisfaction and ease of use of materials of grammar exercises. This study reinforces previous researchs, where the greatest contribution of web-based media development is more to contribute to ease and satisfaction in learning process.

Thus, the researchers hope that there will be an advanced effort to conduct a research that combines development and experimentation to see the concrete and integrated contribution between the use of web-based learning media and improved learning ability.

\section{References}

[1] A. Faridi, Inovasi Pembelajaran Bahasa Inggris Berbasis ICT dalam Rangka Meningkatkan Mutu Pendidikan. Lembaran Ilmu Kependidikan, 2009.

[2] P. Astuti, and Y. Hartono. Developing ICT-Based Teaching Materials of English for Mathematics Course. Proceedings of the 2nd SULE IC 2016, FKIP, Unsri, Palembang, October 7th - 9th, 2016.

[3] B.E. Özad, and O. Kutoğlu, "The use of the internet in media education. TOJET: The Turkish Online Journal of Educational Technology," vol. 9. April 2010.

[4] S. Siahaan, E-Learning (Pembelajaran Elektronik) sebagai Salah Satu Alternatif Kegiatan Pembelajaran, 2001

[5] D. E. Lewis, More Companies Seeing Benefits of E-Learning. A Departure from Training by the Book. The Boston Globe, Globe Staff, 2002.

[6] B. Darab and G. A. Montazer, An eclectic model for assessing elearning readiness in the Iranian universities, 2011.

[7] Y. Anistyasari and R. Sarno, Weighted Ontology for Subject Search in Learning, 2011.

[8] N. Henze, P. Dolog, and W. Nejdl, "Reasoning and Ontologies for Personalized E-Learning in the Semantic Web." Educational Technology \& Society, pp. 82-97, 2004.

[9] H. Jia, M. Wang, W. Ran, S.J. Yang, J. Liao, and D.K. Chiu, Design of a performance-oriented workplace e-learning system using ontology, 2011.

[10] R. E. Indrajut, Arsitektur Sekolah Modern Indonesia, Presentasi Sajian, 2004.

[11] M. Gall, P. Joyce, and W. Borg, Educational Reseach. New York, Pearson Publisher, 2007.

[12] N. Chomchiawchan, and D. Khampusean, "The Effectiveness of Web-Based Lesson in Teaching Conjunctions.” International Conference on Education and Management Innovation, IPEDR , vol.30, 2012. 
[13] Y. Atmanegara, S. Agustina, and D. Tiara, "Web-Based Resources in EFL Learning: An Enhancement of Students." Digital Literacy. Advances in Language and Literary Studies, vol. 4, 2013.

[14] M.S. Lyashenko, Implementation of Web-Based Technologies into Teaching and Learning Practices in the University. International Journal of Information and Education Technology, vol. 6, 2016.

[15] S.J. Samaei and A.M. Tonekaboni, Enhancing Performance Knowledge of Grammar: Modern-based Instruction Methods Vs. Conventional Methods. International Journal of Multidisciplinary and Current Research, 2015. 